\title{
SENTRA PERTANIAN KOTA JAKARTA PUSAT
}

\author{
Fahira Muntaz ${ }^{1)}$, J.M Joko Priyono Santosa ${ }^{21}$ \\ 1)Program Studi S1 Arsitektur, Fakultas Teknik, Universitas Tarumanagara, fahiramuntaz07@gmail.com \\ 2) Program Studi S1 Arsitektur, Fakultas Teknik, Universitas Tarumanagara, jokop@ft.untar.ac.id
}

Masuk: 04-07-2021, revisi: 15-08-2021, diterima untuk diterbitkan: 23-10-2021

\begin{abstract}
Abstrak
Perubahan iklim rentan terjadi di kota besar termasuk kota Jakarta karena banyaknya emisi gas rumah kaca yang diakibatkan dari banyak dibangunnya gedung-gedung dan minimnya lahan hijau. Selain itu kota Jakarta dan kota-kota besar pada umumnya tidak dapat mencukupi kebutuhan makanannya sendiri. Perubahan iklim merupakan salah satu ancaman yang sangat serius terhadap sektor pertanian. Diharapkan dengan adanya bangunan sentra pertanian kota ini mampu menciptakan arsitektur untuk sektor pertanian yang tahan terhadap perubahan iklim serta mewadahi petani milenial dan menjadi contoh pertanian di masa depan serta menerapkan arsitektur yang berkelanjutan dapat menjadi representasi dan contoh bangunan berwawasan lingkungan di Jakarta. Perancangan bangunan pusat pertanian kota ini terletak di jalan Raya Kramat Kwitang, Kecamatan Senen, Kota Jakarta Pusat, DKI Jakarta. Analisis data dilakukan dengan menggunakan teori yaitu analisis berdasarkan aspek lingkungan, aspek bangunan dan aspek manusia. Bangunan pusat pertanian kota mewadahi fungsi utama sebagai tempat pembudidayaan tanaman pertanian dan fungsi sekunder sebagai sarana edukasi dan public space. Hasil yang akan dicapai adalah bangunan yang berkonsep dasar rancangan yang berpacu pada sustainable architecture dan juga biophilic dengan merancang unsur alam kedalam bangunan vertikal.
\end{abstract}

Kata kunci: Jakarta Pusat; Kota; Pertanian

\begin{abstract}
Climate change is vulnerable to occur in major cities including the city of Jakarta because of the many greenhouse gas emissions resulting from the construction of many buildings and the lack of green land. In addition, the city of Jakarta and major cities in general can not meet their own food needs. Climate change is a very serious threat to the agricultural sector. It is hoped that the city's agricultural center buildings will be able to create architecture for the agricultural sector that is resistant to climate change and accommodate millennial farmers and become examples of agriculture in the future and apply sustainable architecture can be a representation and example of environmentally minded buildings in Jakarta. The design of the city's agricultural center building is located on Kramat Kwitang Highway, Senen Subdistrict, Central Jakarta City, DKI Jakarta. Data analysis is done using theory i.e. analysis based on environmental aspects, building aspects and human aspects. The city's agricultural center building accommodates the main function as a place to cultivate agricultural crops and secondary functions as a means of education and public space. The result that will be achieved is a building that has a basic design concept that competes on sustainable architecture and also biophilic by designing natural elements into vertical buildings.
\end{abstract}

Keywords: Central Jakarta; Farm; Urban 


\section{PENDAHULUAN}

\section{Latar Belakang}

Perubahan iklim merupakan ancaman yang sangat serius dalam sektor pertanian. Komite Adaptasi Global menyatakan bahwa pada tahun 2030 akan menjadikan 100 juta masyarakat di negara berkembang mengalami kemiskinan akibat perubahan cuaca ekstrem. Berdasarkan hasil tren temperatur pengolahan di Indonesia, temperatur akan mengalami peningkatan sebesar $0,03^{\circ} \mathrm{C}$ per tahun, sehingga dalam 30 tahun temperatur di Indonesia akan meningkat sebesar $0,9^{\circ} \mathrm{C}$. Musim hujan yang pendek namun dengan curah hujan yang tinggi dikarenakan perubahan iklim mengakibatkan perubahan cara pembudidayaan tanaman. Kemudian, kenaikan suhu dan kelembaban merangsang pertumbuhan dan perkembangan hama tanaman. Dari penjelasan tersebut dapat disimpulkan bahwa perubahan iklim secara ekologis telah mengubah ekosistem di dalamnya karena merugikan sektor pertanian. Melalui penjelasan tersebut, perubahan iklim ekologis telah mengubah ekosistem di dalamnya karena tidak mendukung bagi sektor pertanian.

Jakarta Pusat merupakan wilayah perkotaan yang sudah tidak memiliki lahan hijau diantara kota Jakarta lainnya sehingga dapat memicu terjadinya krisis pangan di daerah tersebut. Dinas Ketahanan Pangan Kelautan dan Perikanan (KPKP) mendukung penuh dengan mengembangkan urban farming di kawasan Jakarta yang bisa menjadikan sarana penghijauan dan edukasi. Maka dari itu perlu diciptakannya ruang yang mewadahi kegiatan pertanian yang dapat beradaptasi dengan iklim dan wilayah perkotaan demi kesejahteraan dimasa depan. Perlunya wadah atau tempat tersebut menjadi latar belakang dari munculnya proyek "Sentra Pertanian Kota Jakarta Pusat".

\section{Rumusan Permasalahan}

Dari latar belakang tersebut, terdapat beberapa masalah yang ditemukan dan dapat menjadi bahan penelitian antara lain perubahan iklim ekstrem yang terjadi di kota besar dapat mengubah ekosistem pertanian, terlebih lagi lahan hijau yang presentasenya menurun dari tahun ke tahun dapat menyebabkan terjadinya sebuah fenomena krisis pangan. Fenomena ini diawali dari terjadinya kuantitas panen yang menurun dan berdampak pada nilai tukar petani yang ikut menurun, jika fenomena ini terjadi pada jangka waktu panjang maka dapat menyebabkan gizi buruk.

\section{Tujuan}

Tujuan dibuatnya proyek ini yaitu diharapkan dapat menciptakan arsitektur untuk sektor pertanian yang tahan terhadap perubahan iklim sehingga tercipta swasembada pangan serta mewadahi petani muda dan menjadi contoh pertanian di masa depan.

\section{KAJIAN LITERATUR}

\section{Urban Farming}

Menurut Bareja (2010) urban farming atau pertanian kota adalah konsep pertanian dengan memanfaatkan keterbatasan lahan untuk melakukan pembudidayaan tanaman atau memelihara hewan ternak yang dilakukan di wilayah kota untuk memperoleh bahan pangan atau kebutuhan lain dan tambahan finansial, termasuk didalamnya pemrosesan hasil panen, penjualan dan distribubsi produk hasil panen tersebut.

\section{Jenis Urban Farming}

Dalam teksnya, Urban Hidroponik atau Sejarah dan Pengertian Urban Farming (2016) ada beberapa jenis urban farming yaitu Tipe Produktif untuk pemenuhan kebutuhan pangan yang bersifat personal, Tipe Estetik yang fokusnya sebagai wadah rekreasi dengan menanam jenis tanaman pangan ataupun hias, Tipe Ekologis yang berfokus pada 3R (Reduce, Reuse, Recycle) 
untuk keselamatan lingkungan dan Tipe Industri yang bertujuan memproduksi pangan untuk kebutuhan pasar lokal dengan skala besar di wilayah kota.

\section{Urban Farming Terkait Ketahanan Pangan}

Nainggolan (2006) menyatakan bahwa sektor pertanian sangat penting di Indonesia karena keharusannya memasok kebutuhan pangan penduduk yang berjumlah 219,3 juta pada tahun 2005 dan diprediksi akan terus bertambah sebesar 1,25 persen. Pemahaman mengenai ketahanan didasari pada Peraturan Pemerintah No. 68 Tahun 2002 tentang Ketahanan Pangan yang menyebutkan bahwa ketahanan pangan merupakan kondisi terpenuhinya kebutuhan pangan bagi rumah tangga yang tercermin dari tersedianya pangan secara cukup, baik dari jumlah maupun mutunya, aman, merata dan terjangkau.

\section{Aeroponik}

Menurut Nengsih (2019) aeroponik adalah salah satu cara menanam sayuran di udara tanpa media tanah, dengan disemprotkannya nutrisi dalam bentuk kabut pada akar tanaman. Air dan nutrisi disemprotkan menggunakan sprinkler. Aeroponik berasal dari kata aero yang artinya udara dan ponus yang artinya daya. Jadi aeroponik adalah memberdayakan udara. Aeroponik adalah satu jenis hidroponik (memberdayakan air) karena air yang berisi kandungan hara disemprotkan dalam bentuk kabut yang akan diserap oleh akar tanaman.

\section{METODE}

Metode pengumupulan data yang dilakukan yaitu metode yang terdiri dari pengumpulan data primer dan sekunder. Data primer berupa observasi atau mengamati serta mencatat secara sistematis terhadap tapak yang akan dijadikan sebagai Sentra Pertanian Kota Jakarta Pusat. Sedangkan data sekunder berupa studi literatur terkait teori dan data mengenai perancangan dan studi preseden yang mempunyai kemiripan program atau proyek dibedah lalu dijadikan salah satu dasar dan pembelajaran dari perancangan ini.

Bangunan ini mengadaptasi metode desain biophilic: nature in the space. Metode ini merancang unsur alam kedalam sebuah bangunan vertikal untuk mengembalikan lahan pertanian yang sudah terpakai untuk kebutuhan konstruksi di perkotaan. Pola yang digunakan dalam metode ini adalah Visual connection with nature pola yang memberi akses kepada manusia dengan pemandangan alam, sistem kehidupan, dan proses alami. Presence of Water yaitu pola yang menghadirkan unsur air. Selain dapat menenangkan dan menstimulasi manusia secara psikologis, unsur air juga berpengaruh pada kondisi termal pada bangunan maupun terhadap lingkungan sekitarnya. Pertimbangan desain pada pola ini adalah moving water dan Connection with natural system dengan Kesadaran terhadap adanya proses alami, yang selalu berubah dan bersifat musiman serta karakteristik perubahan temporal dari ekosistem yang sehat.

Pembudidayaan tanaman yang ada pada bangunan ini yaitu menggunakan metode penanaman indoor farming dengan teknik penanaman aeroponik. Teknik penanaman aeroponik ini dibantu oleh growth light led sebagai pengganti cahaya matahari yang dibutuhkan tanaman untuk proses fotosintesis. Pembudidayaan tanaman dilakukan dari proses pembibitan, pemanenan, hingga pemasaran.

\section{DISKUSI DAN HASIL}

\section{Analisis lokasi}

Tapak berada di Jl. Kramat Kwitang, Kec. Senen, Kota Jakarta Pusat. Peruntukan tapak ini merupakan lahan zona campuran K1 yaitu zona perkantoran, perdagangan dan jasa. Kondisi eksisting tapak berupa lahan kosong. Tapak memiliki luas $8.750 \mathrm{~m}^{2}$ dengan KDB sebesar 60, KLB 


\section{3,5, KB 8, KDH 30 dan KTB 55.}
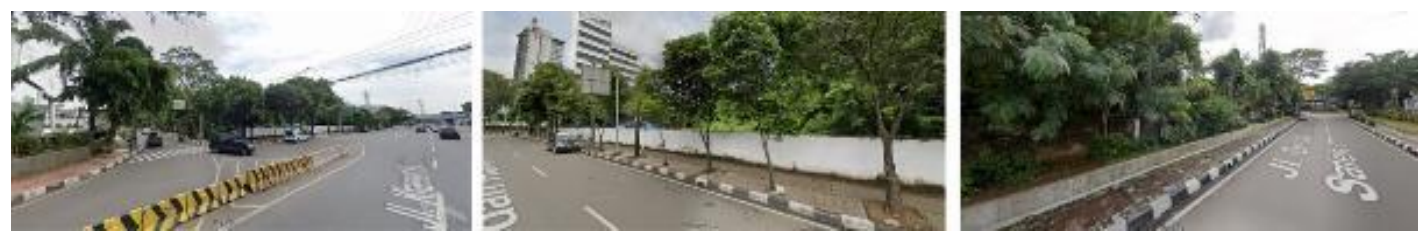

Gambar 1. Lokasi Tapak

Sumber: Google Maps

Dalam menganalisis tapak terdapat aspek yang diperhatikan yaitu :
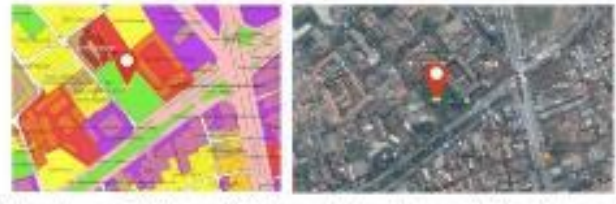

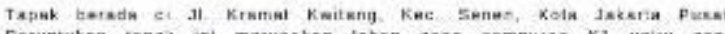
Peruntukan rapas ini merusakan lahan zonn campusas K1 yaizu zonn perkantoran, perzsuangan dan jasa. Konsisi fksisting bapak berupa lahan KDH 3 A

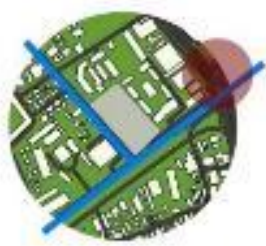

AKSTS DAN SIRKULASI

Tapak dapat d akses me poguraksm kenzaraan pritasil dan kendarasn Topas dapat diakses melalu il Kramat Kmitang dan 1. Dr. abdal Rasman Solat: $h$ i

KEPADATAN KENDARAAN

Topak berso tidak jaus dari

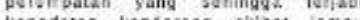

kegadatan kendaraan akizzt lampd

meras Ji. Senes raya

Solusi:

Pelempatan sinte mases di jachkan

Perion

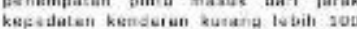
matar:

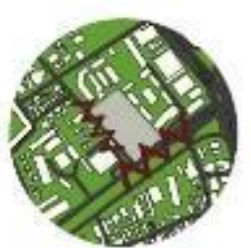

KESISINGAN

Kebisingan pada jalan Jl Or. Abdul Gizhan Sa oh 1 relative ketil atad rencah serangkan kobizingan gado

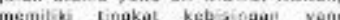
cukug tinga , tag mentor kan eles a: au datreak tang kutkng tiak bolue kantor p*ngeleis diesns cibutuhikat ketenanģก.

Snitusi :

PMiakkan benguesn mimina 70 mein

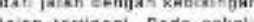
Mnn teringol pada seketing sapa dapat metodukst kebis: pobon matebn das jati

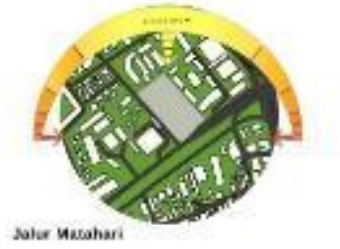

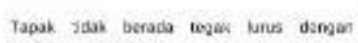

\section{sition:}

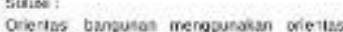

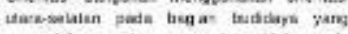

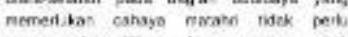

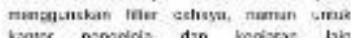

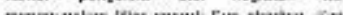

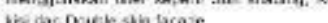

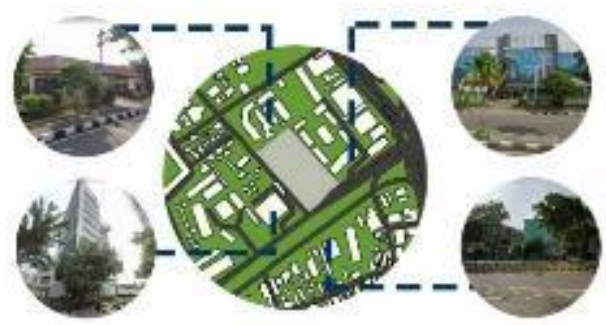

view

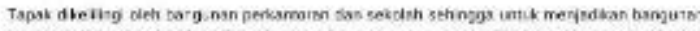

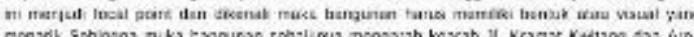

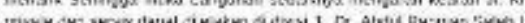

Gambar 2. Analisis Tapak

Sumber: Penulis, 2021

\section{Aktivitas dan Program}

Berdasarkan hasil pengumpulan data serta metode yang menjadi tolok ukur perancangan ini, maka program utama dari proyek ini adalah urban farming sebagai area budidaya dimana tanaman diproses dari biji hingga menjadi tanaman yang siap panen dengan teknik aeroponik. Pengunjung juga dapat berinteraksi langsung dengan tanaman yang dibudidayakan. Gallery Pertanian sebagai fungsi penunjang pada bangunan ini dimana pengunjung dapat melihat sejarah pertanian dari masa tradisional hingga pertanian yang modern. Toko buku khusus menjual buku mengenai pertanian dibuat agar menjaga kelokalitasan kawasan kwitang yang merupakan kawasan yang dikenal dengan toko bukunya. Agromart sebagai tempat untuk menjual hasil panen dari urban farming dan pupuk olahan hasil limbah dari urban farming tersebut. 

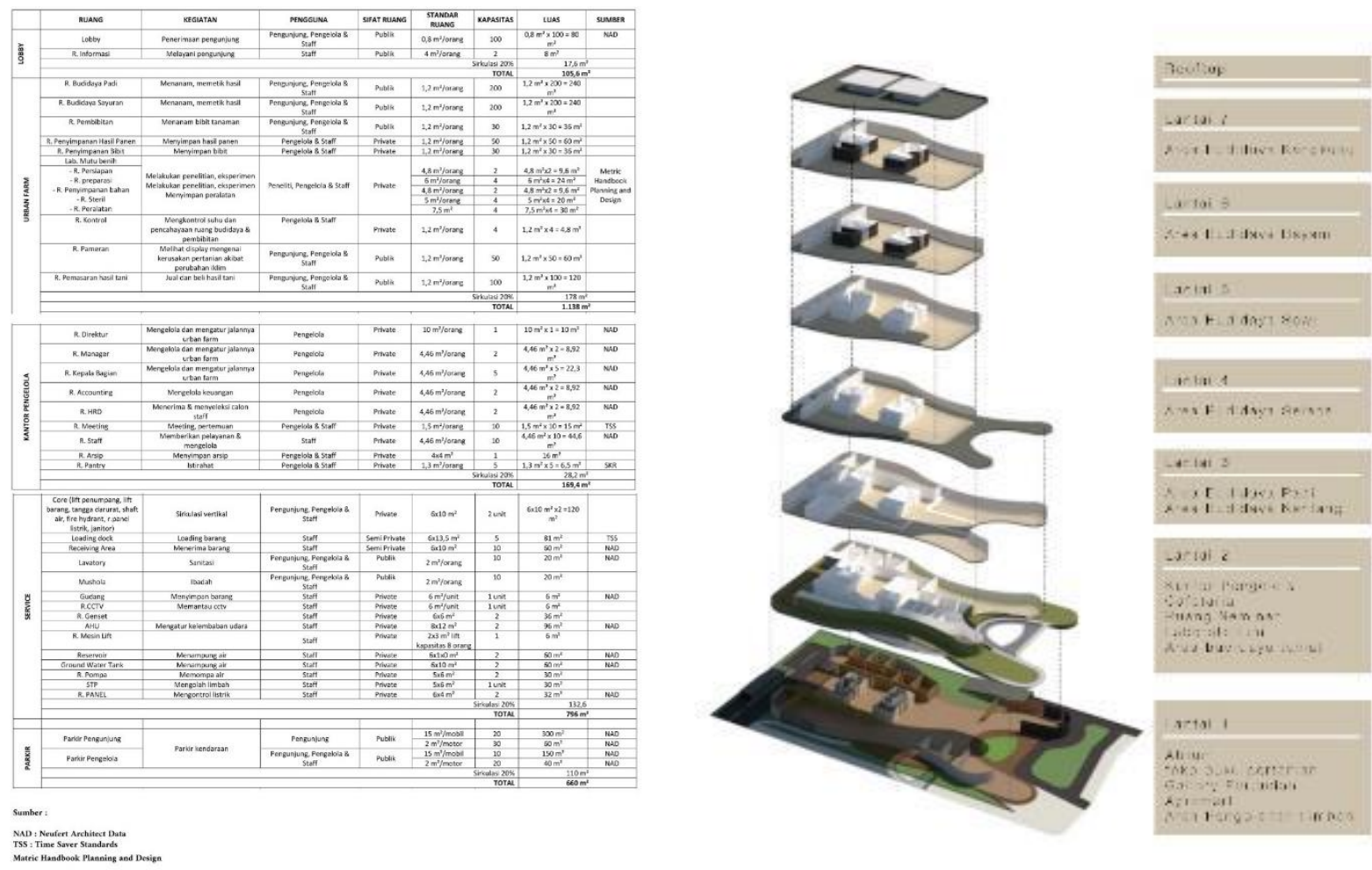

Gambar 3. Program Ruang

Sumber: Penulis, 2021

\section{Konsep Urban Farm}

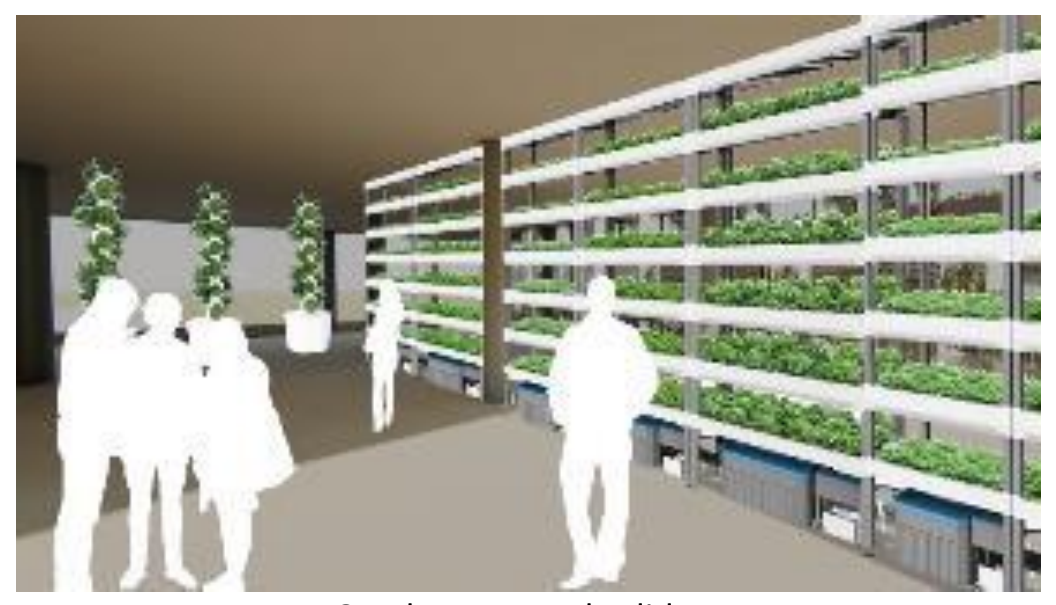

Gambar 4. Area budidaya

Sumber: Penulis, 2021

Urban Farm menggunakan sistem indoor farming dengan memanfaatkan teknologi modern sehingga dapat memberikan hasil produk pertanian yang berkualitas dan bermutu. Sistem Indoor farming dipilih karena mampu mengurangi cemaran gas rumah kaca karena selama proses budidaya tidak memerlukan pupuk dan lahan pertanian yang luas. 

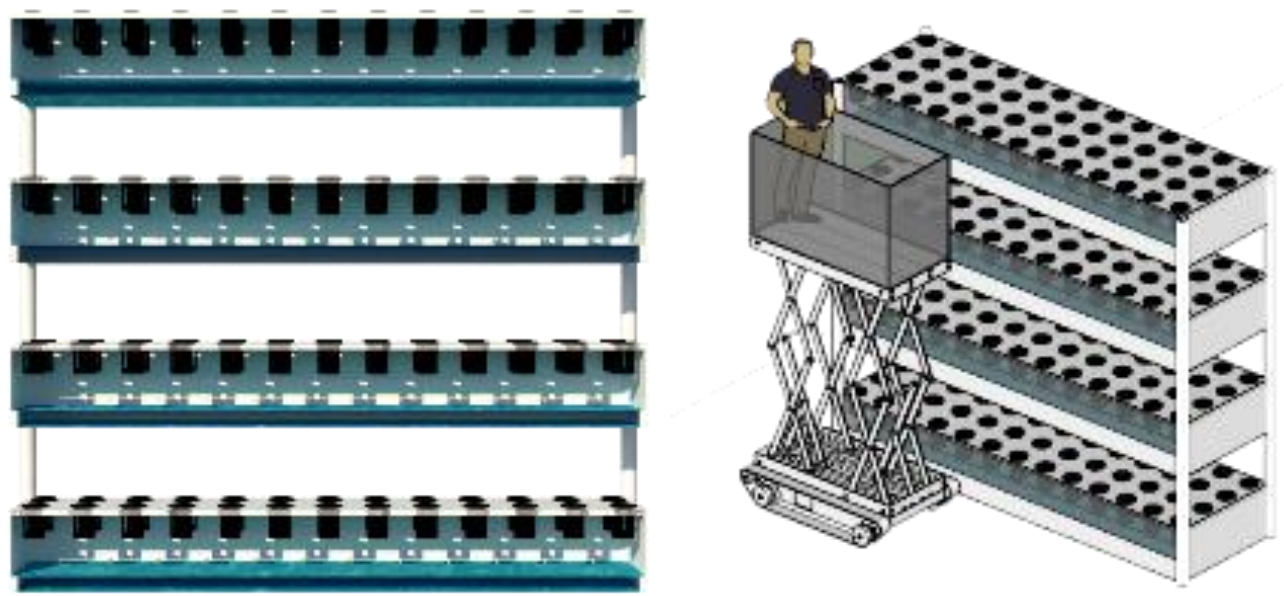

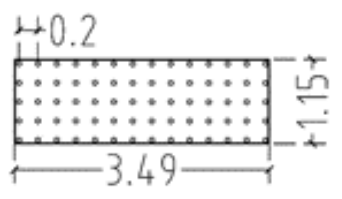

MODUL UNIT KANGKUNG

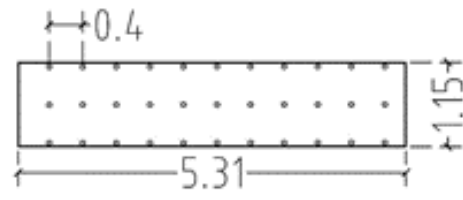

MODUL UNIT BAYAM
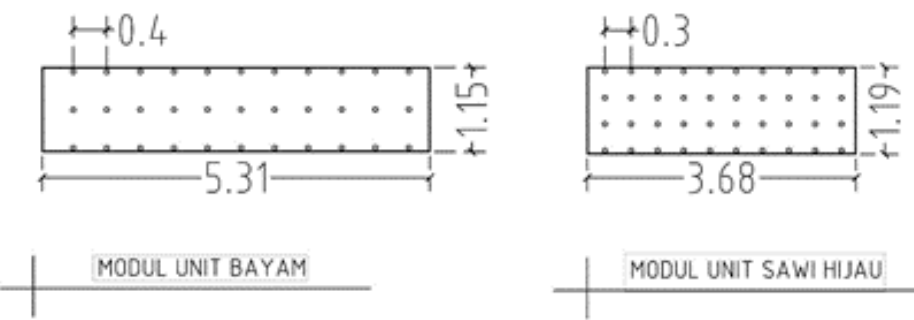

Gambar 5. Modul Tray Aeroponik

Sumber: Penulis, 2021

Urban farm menggunakan modul tray dengan sirkulasi antar unit modul yaitu dengan jarak 2 meter. Untuk memanen hasil produksi aeroponik menggunakan electric scissor lift dengan lebar mesin 1,17 m dan panjang 2,5 m dan ketinggian Platform: 9,68 m. Mesin pompa diletakkan diatas unit tray yang dialiri melalui sprinkler yang berada di masing-masing bawah tray tiap tanaman. Tinggi antar tray tergantung berbeda setiap jenis sayuran tergantung pada tinggi jenis sayuran. Untuk bayam jarak antar tray $80 \mathrm{~cm}$, untuk kangkung $90 \mathrm{~cm}$ dan untuk sawi hijau 90 $\mathrm{cm}$. jarak tanaman ke lampu led yaitu $60 \mathrm{~cm}$.

\section{Konsep Rancangan Gubahan Massa Bangunan}

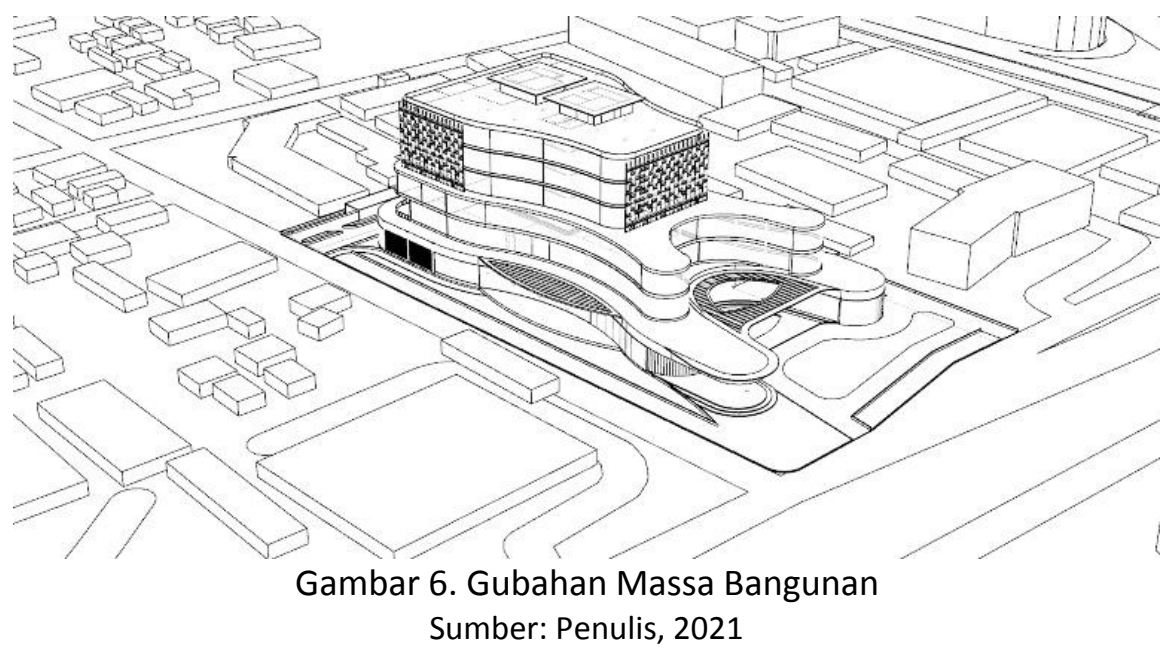

Gubahan massa terbentuk dari konsep desain biophilic yang berprinsip pada Thermal \& airflow variability dengan menerapkan bangunan dengan konsep open space dan terbuka pada bagian 
podium.

\section{Konsep Peletakkan Entrance}

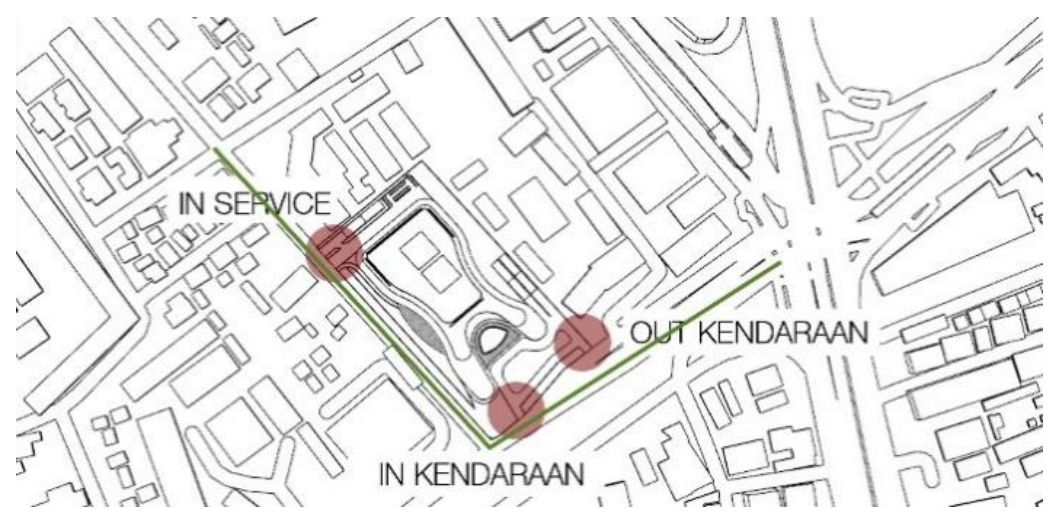

Gambar 7. Peletakkan Entrance

Sumber: Penulis, 2021

implementasi desain biophilic mengambil point complexity dan order yaitu dengan pemilihan lokasi entrance yang mempertimbangkan arus lalu lintas dan menambahkan unsur alam pada letak entrance tapak.

\section{Konsep Selubung Bangunan}

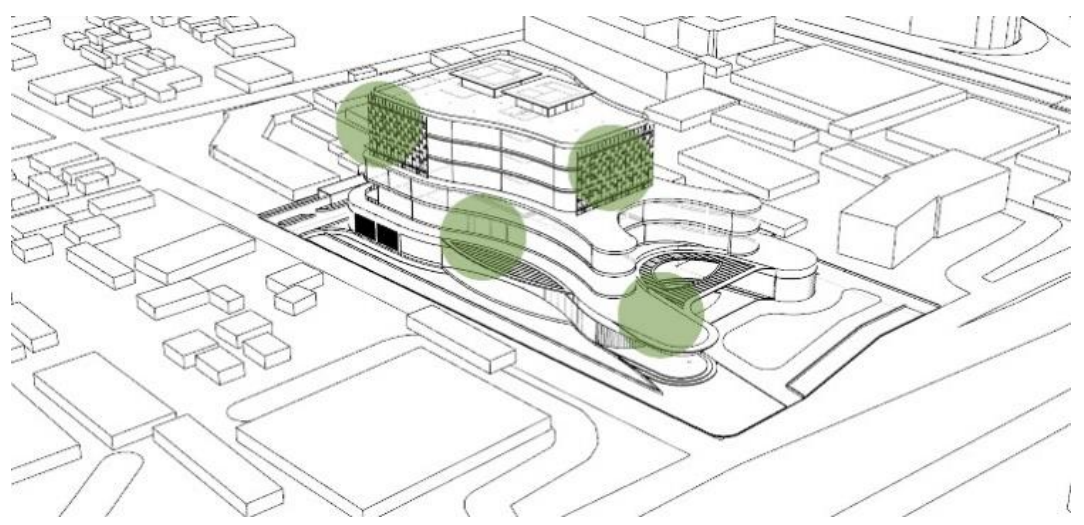

Gambar 8. Konsep Selubung Bangunan

Sumber: Penulis, 2021

Pada bangunan Pusat Pertanian Kota ini menerapkan green Roof dan green wall terutama pada sisi bangunan yang menerima banyak sinar matahari. Green roof dan green wall yang berfungsi untuk menurunkan suhu, mengurangi polusi dan menstabilkan jumlah gas rumah kaca.

\section{Konsep Rancangan Struktur dan Utilitas}

Struktur utama berupa kolom, balok dan plat. Pola struktur yang digunakan adalah pola grid dengan bentangan $8 \mathrm{~m} \times 8 \mathrm{~m}$. Sedangkan dimensi kolom yang digunakan adalah $60 \mathrm{~cm} \times 60 \mathrm{~cm}$ dan dimensi balok $\mathrm{L}=40 \mathrm{~cm}$ dengan tinggi $70 \mathrm{~cm}$.

\section{Konsep Material}

Pada bangunan ini menggunakan green material. Green Material dipilih karena tidak memiliki potensi merusak lingkungan dan mengganggu kesehatan bagi penggunanya. 


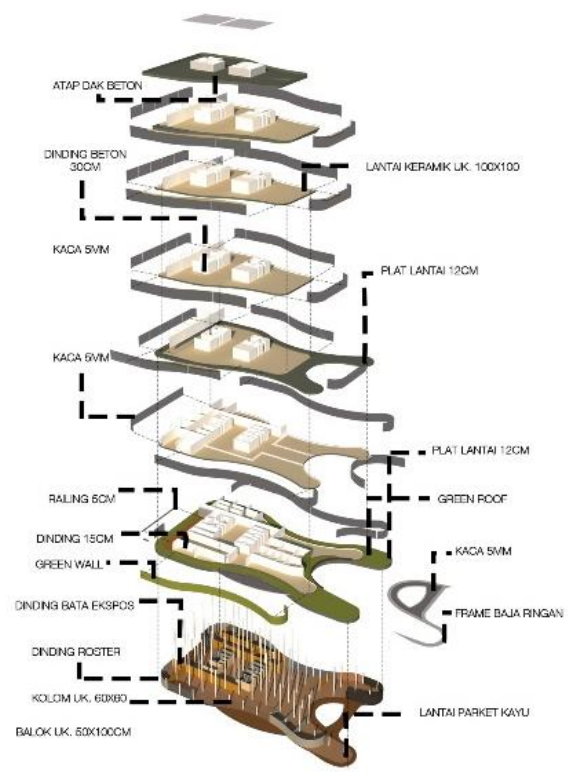

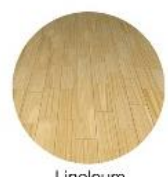

Linoleum

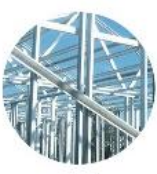

Baja
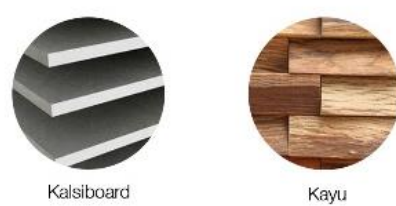

Gambar 9. Material

Sumber: Penulis, 2021

\section{Penerapan Ide Desain pada Bangunan}

Visual Connection with Nature, natural occuring dengan membuat bukaan pada atap yang berfungsi sebagai keluar masuknya cahaya dan udara. Simulated nature, pengunjung dapat langsung berinteraksi dengan berabagai jenis tanaman yang dibudidayakan selain itu tanaman yang mempengaruhi suhu ruangan di dalamnya. Presence of water dengan menerapkan konsep rainwater harvesting yang menampung dan menyaring air hujan berlebih, sehingga dapat menghasilkan air bersih yang dapat dialirkan keseluruh bangunan dan dapat digunakan kembali untuk kegiatan budidaya dan sanitasi pada bangunan. Connection with Natural System, Penerapan dari pola biofilik ini yaitu dengan menghadirkan tanaman dalam ruangan dan pengguna dapat melihat secara langsung sistem budidaya aeroponik dan berinteraksi secara langsung.

\section{Visualisasi Proyek}
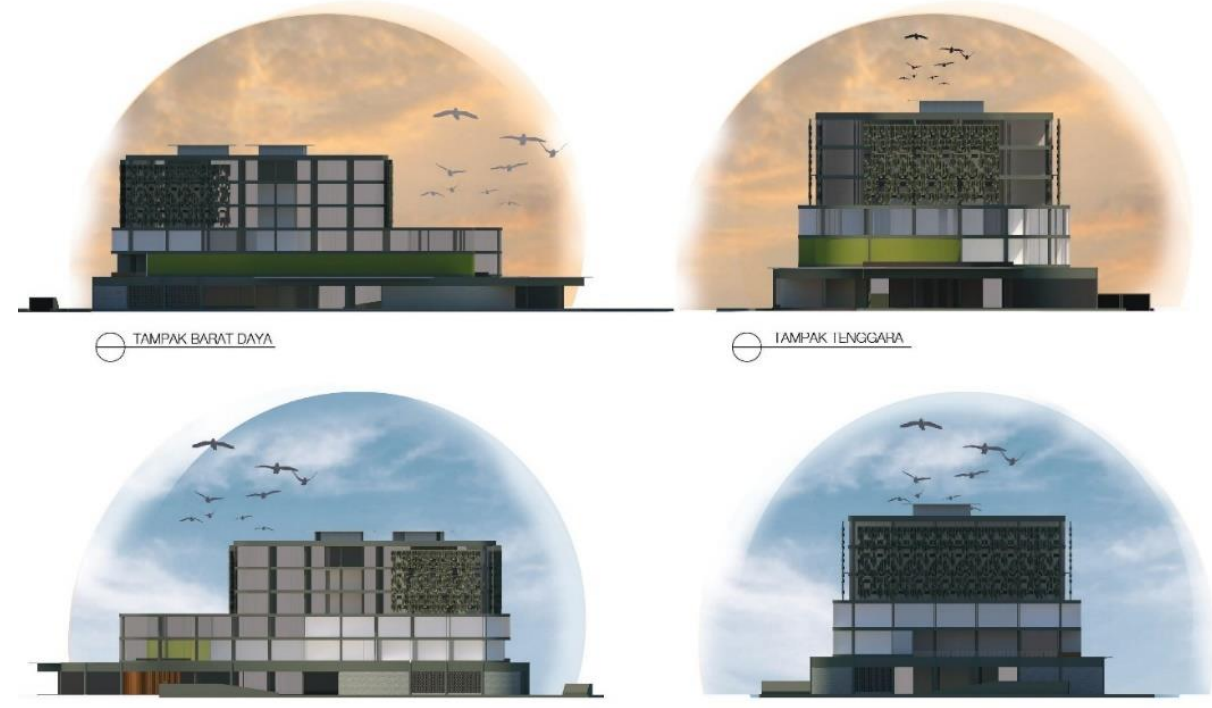

$\bigcirc$ IAMPAK IMUUHLAUI

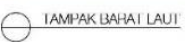

Gambar 10. Tampak

Sumber : Penulis, 2021 


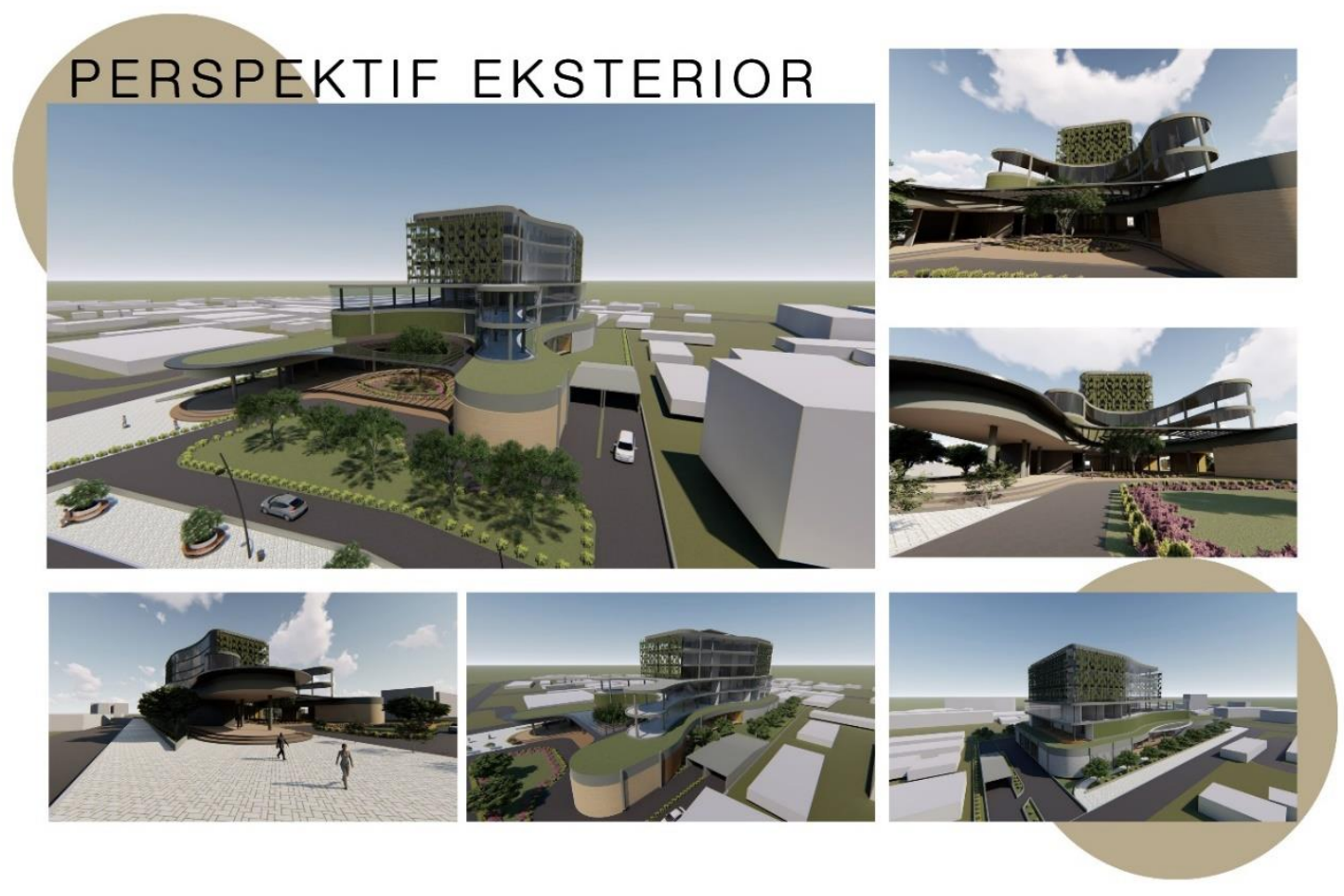

Gambar 11. Perspektif Eksterior

Sumber : Penulis, 2021

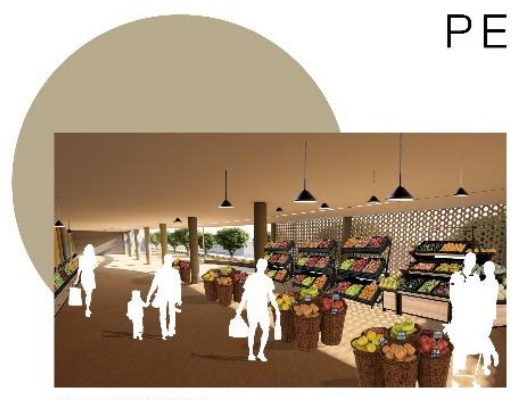

PERSPEKTIF INTERIOR

Perspektif Agromart
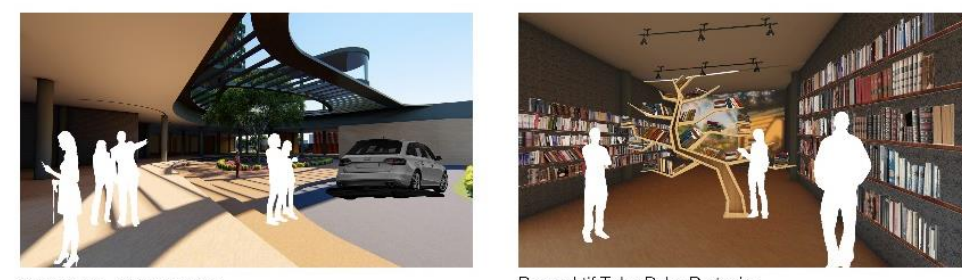

Perspektif Lobby Drop Off

Perspektif Toko Buku Pertanian
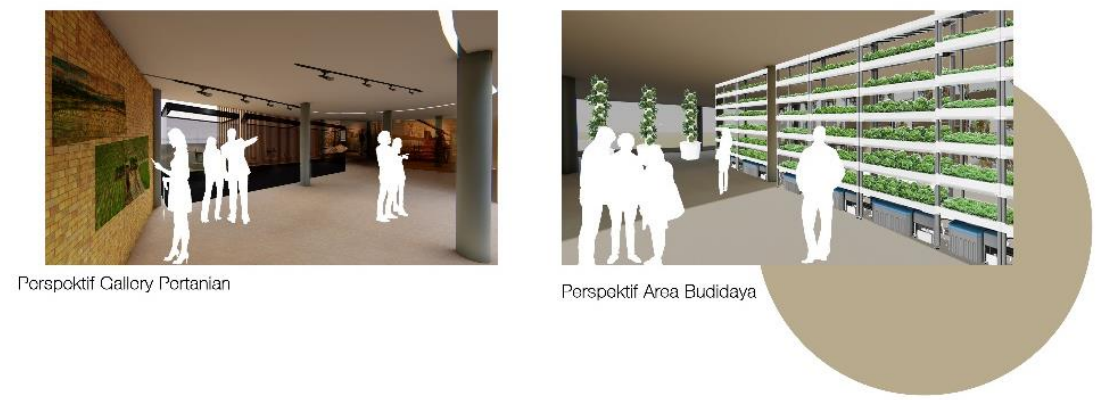

Gambar 12. Perspektif Interior

Sumber : Penulis, 2021

\section{KESIMPULAN DAN SARAN}

\section{Kesimpulan}

Untuk mengatasi perubahan iklim yang mengancam sektor pertanian dan menciptakan swasembada pangan maka diciptakanlah bangunan mid-rise di wilayah Jakarta yang mewadahi kegiatan pertanian yang menggunakan sistem indoor farming dengan dua lantai podium dan 
lima lantai tower dengan fungsi yang berbeda namun tetap terintegrasi antara satu dengan yang lain. Bangunan ini mengadopsi jenis urban farming tipe industri yang membudidayakan tanaman padi dan berbagai jenis sayuran. Perancangan ini menerapkan konsep dasar sustainable architecture dan biophilic. Terdapat tiga pola metode dalam biophilic : nature in the space yang digunakan dalam perancangan bangunan ini yaitu visual connection with nature, presence of water dan connection with natural system.

Sentra Pertanian Kota Jakarta Pusat ini mengintegrasikan fungsi budidaya, produksi, edukasi, penelitian, dan pemasaran serta berkontribusi terhadap perbaikan lingkungan Kota Jakarta dengan menerapkan konservasi air. Konservasi air dengan menerapkan sistem rainwater harvesting yang dimanfaatkan untuk sarana budidaya dan juga untuk sanitasi pengguna dalam gedung. Budidaya yang dilakukan pada bangunan ini mengambil teknik penanaman aeroponik, dimana penanaman ini menggunakan sistem indoor farming sehingga pelaksanaan budidaya tidak dipengaruhi oleh perubahan iklim.

\section{Saran}

Perancangan Sentra Pertanian Kota Jakarta Pusat ini menggunakan sistem penanaman aeroponik, namun pada aspek teknik penanaman aeroponik ini belum seutuhnya diaplikasikan, selain itu tidak semua jenis tanaman digunakan. Maka dari itu diharapkan untuk peneliti atau penulis lain yang ingin mengambil judul penelitian serupa untuk dapat lebih berinovasi dari segi desain maupun teknik penanaman pada urban farming sehingga diharapkan dapat lebih bermanfaat bagi civitas akademik dan masyarakat.

\section{REFERENSI}

Bareja. (2010). Urban Farming.

Bargumono. (2012, Desember). Ekologi Pertanian.

Duerk, D. P. (1993, September 17). Architectural Programming: Information Management for Design.

Hidroponik, U. (2016, Februari). Sejarah dan Pengertian Urban Farming. Retrieved april 18, 2021, from http://www.urbanhidroponik.com/2016/02/sejarah-pengertian-urbanfarming-indonesia.html

Nainggolan. (2006). Kebijakan Umum Ketahanan Pangan, 78.

Nengsih, S. (2019, Oktober 19). Menanam Dengan Sistem Aeroponnik. Retrieved April 19, 2021, from http://cybex.pertanian.go.id/mobile/artikel/76083/MENANAM--DENGAN-SISTEM--AEROPONIK/

Rahimah, D. S. (2010). BUDIDAYA BAYAM (var Amaranth 936 white leaf) DENGAN SISTEM HIDROPONIK DI PARUNG FARM, BOGOR, JAWA BARAT.

Suhardiyanto, H. (2010). Teknologi Hidroponik Untuk Budidaya Tanaman.

Suryandari, R. Y. (2010). Pengembangan Pertanian Perkotaan Impian Mewujudkan Kota yang Berkelanjutan. PLANESA, 1 Nomor 2, 107-112.

Sutiyoso, Y. (2003). Ramuan Pupuk Hidroponik: Tanaman Sayur, Tanaman Buah, Tanaman Bunga.

W. D. Browning, C. O. (2014). 14 Patterns Of Biophilic Design: Improving Health \& Well-Being In The Built Environment.

Wikipedia, K. (n.d.). Ekologi. Retrieved April 19, 2021, from https://id. wikipedia.org/w/index.php?title=Ekologi\&oldid=18164100 